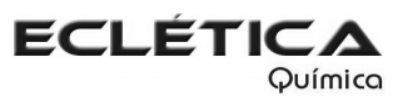

www.scielo.br/eq

www.ecletica.iq.unesp.br

Volume 33, número 4, 2008

\title{
Spectrophotometric determination of metronidazole through Schiff's base system using vanillin and PDAB reagents in pharmaceutical preparations
}

\author{
K. Siddappa*, M. Mallikarjun, P. T. Reddy and M. Tambe \\ Department of Studies and Research in Chemistry Gulbarga University, Gulbarga-585 106, India \\ *siddappa_65@reiffmail.com
}

\begin{abstract}
Two simple sensitive and reproducible spectrophotometric methods have been developed for the determination of metronidazole either in pure form or in their tablets. The proposed methods are based on the reduction of the nitro group to amino group of the drug. The reduction of metronidazole was carried out with zinc powder and $5 \mathrm{~N}$ hydrochloric acid at room temperature in methanol. The resulting amine was then subjected to a condensation reaction with aromatic aldehyde namely, vanillin and p-dimethyl amino benzaldehyde (PDAB) to yield yellow colored Schiff's bases. The formed Schiff's bases are quantified spectrophotometrically at their absorption maxima at $422 \mathrm{~nm}$ for vanillin and $494 \mathrm{~nm}$ for PDAB. Beer's law was obeyed in the concentration ranges 10 to $65 \mu \mathrm{g} \mathrm{mL}^{-1}$ and 5 to $40 \mu \mathrm{g} \mathrm{mL}^{-1}$ with a limit of detection (LOD) of $0.080 \mu \mathrm{g} \mathrm{mL}^{-1}$ and $0.090 \mu \mathrm{g} \mathrm{mL}^{-1}$ for vanillin and $\mathrm{PDAB}$, respectively. The mean percentage recoveries were found to be $100.05 \pm 0.37$ and $99.01 \pm 0.76$ for the two methods respectively. The proposed methods were successfully applied to determine the metronidazole in their tablet formulations and the results compared favorably to that of reference methods. The proposed methods are recommended for quality control and routine analysis.
\end{abstract}

Keywords: spectrophotometry; vanillin; PDAB; metronidazole; pharmaceutical analysis.

\section{Introduction}

5-Nitroimidazoles, such as metronidazole, are extensively used as antiamoebic, antiprotozoal and antibacterial drugs. The discovery of the antibacterial and antitrichomonal properties of the antibiotic azomycin led to the investigation of nitroimidazoles as antiparasitic agents [1,2]. The discovery of the antitrichomonal properties of metronidazole revolutionized the treatment of disease. Although the amoebicidal properties of metronidazole were studied, it was not clinically tested until some years later. In laboratory tests, metronidazole is effective against intestinal amoebiasis in rats and hepatic amoebiasis in hamsters and is also active against Entamoeba histolytica in vitro $[3,4]$. The initial clinical tests of metronidazole indicated that it was capable of curing invasive amoebic dysentery and amoebic liver abscess [5] Subsequent clinical tests have established metronidazole as the drug of choice in the treatment of all forms of amoebiasis in humans[6,7].

Metronidazole is officially determined by titrimetry, potentiometry and HPLC methods. Indian Pharmacopoeia [8] describes the non-aqueous titration method using perchloric acid as titrant and malachite green as indicator for the assay of 
metronidazole. British Pharmacopoeia [9] describes potentiometric and non-aqueous titration methods using perchloric acid as titrant. United States Pharmacopoeia [10] describes HPLC and nonaqueous titration methods for the assay of metronidazole. Visible spectrophotometry, because of simplicity and cost effectiveness, sensitivity and selectivity, and fair accuracy and precision, has remained competitive in an era chromatographic techniques for pharmaceutical analysis. Several methods have been reported for the determination of metronidazole, including spectrophotometry [11, 13], polarography [14]. Most of the spectrophotometric methods found in the literature for the determination of metronidazole in the visible region involve initial reduction by treatment with Zinc powder and $\mathrm{HCl}[15,22]$ followed by the diazotization and coupling of the resulting amine. All these methods are less sensitive, involve tedious procedures such as heating and extraction, utilize costly reagents and involve an additional diazotization step. In the present study, two spectrophotometric methods for the quantitative estimation of metronidazole have been developed after converting it to its reduced form by using zinc powder and $\mathrm{HCl}$, as well as the reaction of its reduced product with vanillin and PDAB was studied to establish the optimum reaction conditions, optical characteristics, precision and accuracy of the proposed methods. The methods are simple, rapid, sensitive and are successfully applied to determine the metronidazole in their pharmaceutical formulations. Furthermore, they do not need costly instrumentation required for published HPLC methods.

\section{Experimental details}

\section{Apparatus}

An Elico model SL 164 UV-Visible double beam spectrophotometer with $1 \mathrm{~cm}$ matched quartz cell was used for recording spectra and absorbance measurements.

\section{Reagents}

All reagents used were of analytical grade and were obtained from Qualigens fine chemicals, Mumbai. Metronidazole was kindly supplied by Sarabhai Pharmaceuticals Ltd., Baroda,
India. Metronidazole tablets were purchased from a local market. Distilled water was used for the preparation of $\mathrm{HCl}$ solution.

\section{Sample preparation}

Mehanolic solution of vanillin (4\%) and PDAB (3\%) was prepared by dissolving 3 and 4 $\mathrm{g}$ in a $100 \mathrm{~mL}$ volumetric flask containing methanol. A $5 \mathrm{~N} \mathrm{HCl}$ was prepared by dissolving $43.1 \mathrm{~mL}$ of concentrated hydrochloric acid and was diluted to $100 \mathrm{~mL}$ with water.

\section{Reduction of the nitro group and preparation of standard drug solution}

About $100 \mathrm{mg}$ of metronidazol pure or equivalent tablet powder was accurately weighed and dissolved in $20 \mathrm{~mL}$ of methanol. The methanolic solution of metronidazole was treated with $10 \mathrm{~mL}$ of $5 \mathrm{~N}$ Hydrochloric acid and $0.5 \mathrm{~g}$ of zinc powder was added in portions while shaking. After standing for 1hour at room temperature, the solution was filtered using a Whatman filter paper No 41 filter paper to remove the insoluble matter. The residue was washed with $10 \mathrm{~mL}$ portions of methanol three times, and the total volume of the filtrate was made up to $100 \mathrm{~mL}$ with methanol. The final working standard solution of reduced metronidazole containing $100 \mu \mathrm{g} \mathrm{mL}-1$ was prepared by further dilution.

\section{General procedure}

\section{Method A}

In method A, fresh aliquots (1.0- $6.5 \mathrm{~mL}$ ) of standard $100 \mu \mathrm{g} \mathrm{mL}^{-1}$ reduced metronidazole solution were accurately measured and transferred in to a series of $10 \mathrm{~mL}$ volumetric flasks by means of a micro burette. To each of the above aliquots, $2.0 \mathrm{~mL}$ of $4 \%(\mathrm{w} / \mathrm{v})$ of vanillin solution in methanol prepared above were added and mixed thoroughly and then the solution was heated in a water bath at $60-70^{\circ} \mathrm{C}$ for $15 \mathrm{~min}$, and cooled to room temp. After cooling, the volume was brought up to the mark with methanol, mixed well and the absorbance of each yellow colored species was measured after $10 \mathrm{~min}$. at $422 \mathrm{~nm}$ against reagent blank. A calibration graph was constructed by plotting the absorbance against the concentration of the drug. 


\section{Method B}

In method $\mathrm{B}$, fresh aliquots $(0.5-4.0 \mathrm{~mL})$ of standard $100 \mu \mathrm{g} \mathrm{mL}^{-1}$ reduced metronidazole solution were accurately measured and transferred in to a series of $10 \mathrm{~mL}$ volumetric flasks by means of a micro burette. To each of the above aliquots, $0.5 \mathrm{~mL}$ of $3 \%(\mathrm{w} / \mathrm{v})$ of PDAB solution in methanol prepared above were added and mixed thoroughly, and then the solution was heated in a water bath at $60-70^{\circ} \mathrm{C}$ for $15 \mathrm{~min}$, and cooled to room temp. After cooling, the volume was brought up to the mark with methanol, mixed well and the absorbance of each yellow colored species was measured after $10 \mathrm{~min}$. at $494 \mathrm{~nm}$ against reagent blank. A calibration graph was constructed by plotting the absorbance against the concentration of the drug.

\section{Assay procedure}

Twenty tablets of metronidazole were powdered. An accurate quantity of powder equivalent to $100 \mathrm{mg}$ of metronidazole was weighed. The reduction of metronidazole was carried out by using hydrochloric acid and zinc powder. The resulting filtrate was transferred to a $100 \mathrm{ml}$ volumetric flask and made up to the mark with methanol and an aliquot of this solution was treated as described above for the determination of metronidazole. The amount of metronidazole present in the sample was computed from calibration curve.

\section{Results and discussion}

\section{Determination of absorption maximum}

Reduced metronidazole when treated with vanillin and PDAB form a yellow product (Schiff's base) in acidic medium. To determine the absorption maxima, $35 \mu \mathrm{g} \mathrm{mL}^{-1}$ (Method A) and $15 \mu \mathrm{g}$ $\mathrm{mL}^{-1}$ (Method B) of the metronidazole was added in a $10 \mathrm{~mL}$ volumetric flasks. Then each drug solution was reacted with $2.0 \mathrm{~mL}$ vanillin $(4 \%)$ and 0.5 $\mathrm{mL}$ PDAB (3\%). The solution was heated in a water bath at $60-70^{\circ} \mathrm{C}$ for $15 \mathrm{~min}$. After cooling, the volume was brought up to the mark with methanol and mixed well After 10 min., absorption spectra were taken against reagent blank in the range $350-650 \mathrm{~nm}$. The maximum absorption wavelength for metronidazole was found to be 422 $\mathrm{nm}$ for method A and $494 \mathrm{~nm}$ for method B. The absorption spectrums of the colored product against reagent blank of both the methods are shown in Figure 1. Under the experimental conditions each colorless reagent blank showed a negligible absorbance at the corresponding $\lambda_{\max }$.

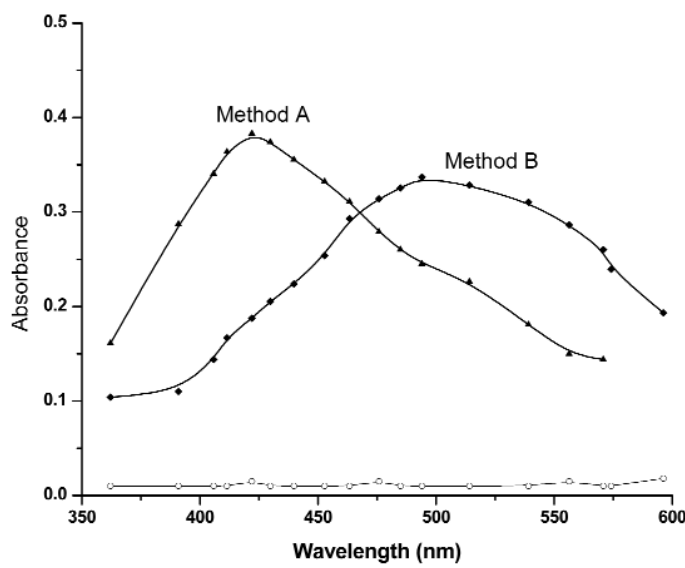

Figure 1. Absorption spectra of Metronidazole (35 $\left.\mathrm{mg} \mathrm{mL}^{-1}\right)$ with vanillin and Metronidazole $\left(15 \mathrm{mg} \mathrm{mL}^{-1}\right)$ with PDAB against reagent blank.

\section{Reaction Sequence}

Reduction of the nitro group of the drug was carried out as explained in the experimental section. When the resulting amine undergoes a condensation reaction in acidic medium with vanillin and PDAB, it forms a yellow Schiff's base with maximum absorbance at 422 and 494 $\mathrm{nm}$. The reaction of PDAB and vanillin with pyrroles has been used qualitatively and quantitatively for many years [23, 25]. The reaction with aromatic amines to give Schiff's base is equally well documented [26]. The Wasicky reaction, utilizing aqueous sulphuric acid (94\%) solution gives color reaction with alkaloids [27] and purines [28]. In 1994 Werner [29] reinvestigated the reaction with nitrogen compounds and found that in a more dilute aqueous system aromatic compounds react in the presence of mineral acid, provide the $-\mathrm{NH}_{2}$ group is directly attached to the benzene nucleus. The probable reaction mechanism based on the reported method [30, 32] is given in Scheme 1. 
<smiles>Cc1ncc(N)n1CCO</smiles>

Metronidazole
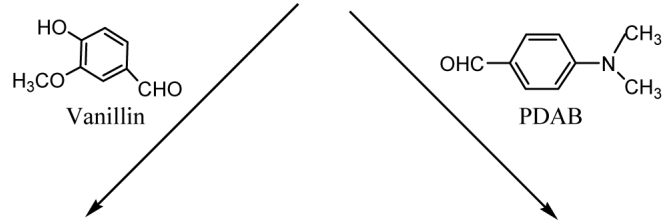

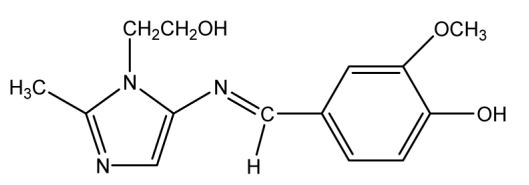

Schiff's base (Method A)

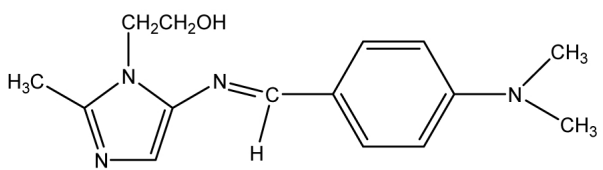

Schiff's base (Method B)

Scheme 1. The proposed reactions involved in formation of colored Schiff's bases in acidic medium.

Determination of effective reagents concentration

To study the effect of concentration and volume of vanillin and PDAB on the maximum absorbance, a number of preliminary experiments were carried out. The effect of vanillin and PDAB concentration was studied at 422 and 494 $\mathrm{nm}$. To a series of solutions containing 40 and 20 $\mu \mathrm{g} \mathrm{mL}-1$ of metronidazole $\left(100 \mu \mathrm{g} \mathrm{mL}{ }^{11}\right)$ followed by varying concentration (1\% to $6 \%$ ) of vanillin and PDAB were added for method $A$ and $\mathrm{B}$, then the solution was heated in a water bath for $15 \mathrm{~min}$., at $60-70^{\circ} \mathrm{C}$ and cooled to room temperature. After $10 \mathrm{~min}$ absorbance of each solution was measured at 422 and $494 \mathrm{~nm}$. It was observed that the analytical signal increased with an increase in reagent concentration up to $5 \%$ $(\operatorname{method} \mathrm{A}$ and $\mathrm{B})$ and thereafter decreases with an increase in reagent concentration. Therefore the concentration of vanillin and PDAB selected was $4 \%$ and $3 \%$ for both the methods. Similarly, by fixing the concentration of vanillin and PDAB as $4 \%$ and $3 \%$ in a series of solutions containing 40 and $20 \mu \mathrm{g} \mathrm{mL}^{-1}$ of metronidazole, different volumes in the range of 1.0-4.0 mL (method A) and $0.1-1.0 \mathrm{~mL}$ (method $\mathrm{B}$ ) were added. Then the solution was heated in a water bath for $15 \mathrm{~min}$., at $60-70{ }^{\circ} \mathrm{C}$ and cooled to room temperature. After $10 \mathrm{~min}$ absorbance of each solution was measured at 422 and $494 \mathrm{~nm}$., it was found that $2.0 \mathrm{~mL}$ of $4 \%$ vanillin solution for method $\mathrm{A}$ and $0.5 \mathrm{~mL}$ of $3 \%$ PDAB for method B was optimal for the formation of color with maximum intensity. Therefore, $2.0 \mathrm{~mL}$ of $4 \%$ vanillin and $0.5 \mathrm{~mL}$ of $3 \%$ PDAB were selected for all measurements.

After optimization of chemical variables, the influence of temperature on the colored product was studied at different temperature (50-80 $\left.{ }^{0} \mathrm{C}\right)$; it was observed that the obtained colored product were stable up to $70^{\circ} \mathrm{C}$. However, no considerable improvements were occurred above $80^{\circ} \mathrm{C}$ therefore $60-70^{\circ} \mathrm{C}$ was selected as optimum temperature for both the methods.

\section{Optical characteristics and validation of the method}

Optical characteristics such as Beer's law limits, molar absorptivity and Sandell's sensitivity, for metronidazole, are given in Table 1. Data of the regression analysis using the least squares method made for the calibration curves are also given in the same table. The accuracy and precision of the method were checked by analyzing six replicate samples within the Beer's law range containing the same amount of each drug. The lower values of RSD indicate the good precision and reproducibility of the method. The validity of the proposed pro- 
cedure for the determination of metronidazole in their pure state was checked by analyzing this drug using the proposed method. The results obtained for pure drug were reproducible with low relative standard deviations (RSD). The limit of quantification (LOQ) was determined by taking the ratio of the standard deviation (SD) of the blank with respect to water and the slope of the calibration curve multiplied by the factor ten. This means that LOQ is

Table 1. Analytical parameters of spectrophotometric methods.

\begin{tabular}{|c|c|c|}
\hline Parameters & Method A & Method B \\
\hline$\lambda \max (\mathrm{nm})$ & 422 & 494 \\
\hline Beer's Law limits $\left(\mu \mathrm{g} \mathrm{mL}^{-1}\right)$ & $10-65$ & $5-40$ \\
\hline 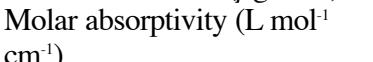 & $1775 \times 10^{4}$ & $03505 \times 10^{4}$ \\
\hline $\begin{array}{l}\text { Sandell's sensitivity }\left(\mu \mathrm{g} \mathrm{mL}^{-1}\right) \\
\text { Regression equation } * *(\mathrm{Y}= \\
\mathrm{bx}+\mathrm{c})\end{array}$ & 0.0096 & 0.0488 \\
\hline Slope(b) & 0.1027 & 0.1866 \\
\hline Intercept(c) & 0.0010 & 0.0439 \\
\hline $\begin{array}{l}\text { Correlation coefficient ( } \mathrm{r} \text { ) } \\
\% \text { Relative Standard }\end{array}$ & 0.9997 & 0.9998 \\
\hline $\begin{array}{l}\text { Deviation (R.S.D)* } \\
\% \text { Range of error } \\
\text { (Confidence)* }^{*}\end{array}$ & 0.2169 & 0.2561 \\
\hline 0.05 level & 0.0086 & 0.0010 \\
\hline 0.01 level & 0.00125 & 0.0014 \\
\hline Limit of Detection $\left(\mu \mathrm{g} \mathrm{mL}^{-1}\right)$ & 0.0800 & 0.0900 \\
\hline $\begin{array}{l}\text { Limit of Quantification }(\mu \mathrm{g} \\
\left.\mathrm{mL}^{-1}\right)\end{array}$ & 0.3160 & 0.2997 \\
\hline Stability (hr.) & 2 & 2 \\
\hline Color & yellow & yellow \\
\hline
\end{tabular}

** $\mathrm{Y}=\mathrm{bX}+\mathrm{c}$, where $\mathrm{Y}$ is the absorbance and $\mathrm{X}$ is the concentration of drug in $\mu \mathrm{g} \mathrm{mL}^{-1}$.

*Average of six determinations. approximately four times greater than LOD. LOD is well below the lower limit of the Beer's law range.

\section{Applicability of the method}

The applicability of the proposed spectrophotometric methods for the assay of metronidazole was tested by analyzing various available commercial formulations. The samples were also analyzed using the official method. The results given in Table 2 of the analysis showed that the data are consistent with the label claim of the formulations. The calibration curves showed a linear response over the concentration ranges used in the general procedures as shown in Figures 2 and 3. The RSD values for the reproducibility and recovery studies show that the method is precise and accurate. In addition it is observed that there is no interference (Table 3) from the excipients used in the formulations. Hence, this method can be adopted for the routine quality control of metronidazole in bulk as well as in formulations.

Table 3. Determination of Metronidazole ${ }^{a}$ in the presence of excipients.

\begin{tabular}{lcc}
\hline Excipients & $\begin{array}{c}\text { Amount taken } \\
\left(\mu \mathrm{g} \mathrm{mL}^{-1}\right)\end{array}$ & $\begin{array}{c}\% \text { Recovery }+ \\
\% \mathrm{RSD}^{\mathrm{b}}\end{array}$ \\
\hline Glucose & 20 & $99.5+0.54$ \\
Sucrose & 20 & $99.47+0.25$ \\
Lactose & 25 & $99.64+0.56$ \\
Dextrose & 20 & $100.1+0.21$ \\
Talc & 25 & $98.96+0.82$ \\
Starch & 20 & $99.20+0.38$ \\
Sodium alginate & 15 & $100.25+0.64$
\end{tabular}

a $30 \mu \mathrm{g} \mathrm{mL}^{-1}$ of Metronidazole Taken.

${ }^{\mathrm{b}}$ Average of six determinations.

Table 2. Determination of Metronidazole in Formulations by the Proposed and Reference Method.

\begin{tabular}{lcccc}
\hline Tablet brand name & $\begin{array}{c}\text { Labelled } \\
\text { Amount } \\
(\mathrm{mg} / \text { tablets })\end{array}$ & Reference method $^{21,22}$ & \multicolumn{2}{c}{ \% Found \pm SD* } \\
\cline { 3 - 5 } & & & Method A & Method B \\
\hline Flagyla & 400 & $99.20 \pm 0.52$ & $99.23 \pm 0.30$ & $99.34 \pm 0.48$ \\
Metronb & 200 & $98.92 \pm 0.66$ & $100.05 \pm 0.37$ & $99.01 \pm 0.76$ \\
\hline
\end{tabular}

*Average of six determinations \pm SD

Marketed by Nicholas Piramal ${ }^{\mathrm{a}}$ and Alkem ${ }^{\mathrm{b}}$ 


\section{Conclusions}

The proposed spectrophotometric methods for the determination of metronidazole are simple, accurate, precise and cheap. The statistical analyses show that the data from the proposed method are in good agreement with those of the reported methods. The color reaction does not require stringent conditions nor any specific reagent or buffer. The colored species was stable for more than two hours, which is sufficient time for the analyst to perform the analysis. Moreover they do not require any pretreatment of the drug and tedious extraction procedure. Hence, the data presented in the manuscript by spectrophotometric methods for the determination of metronidazole in its pure and dosage form demonstrate that the proposed methods are accurate, precise and linear. Thus it can be extended for routine analysis of metronidazole in pharmaceutical industries, hospitals and research laboratories.

\section{Acknowledgements}

The authors are grateful to Sarabhai Pharmaceutical Ltd., India, for providing gift sample of Metronidazole drug and Principal, H.K.E Society's College of Pharmacy, Gulbarga for providing library and other necessary facilities.

Thanks are also to the Professor and Chairman, Department of Studies and Research in Chemistry, Gulbarga University, Gulbarga for providing laboratory facilities to carry out the present work.

Received April 222008

Accepted September 302008

\section{References}

[1] M. E. Wol, John Wiley and Sons, "Text book of Burgers Medicinal Chemistry," fourth ed., New York, 1979.

[2] C. Cosar, L. Julon, Ann. Inst. Pasteur. 96 (1959) 238.

[3] C. Cosar, P. Ganter, L. Julion, Presse Meed. 69 (1961) 1069.

[4] C. Cosar, C. Cusan, R. Horclois, R. M. Jacob, J. Robert, J. S. Tchelitche, R. Vaupre, Arzneim -Forsch. 16 (1966) 23.

[5] S.J. Powell, I. McLeod, A. J. Wilmot, R. Elsdon-Dew, Lancet. 2 (1966) 1329.

[6] S.J. Powell, Bull. N.Y. Acad. Med 47 (1971) 469.

[7] R.B. Khambatta, Ann. Trop. Med. Parasitol. 62 (1968) 139.

[8] Indian Pharmacopoeia, Controller of Publications, New Delhi, 2 (1996) p 764.

[9] British Pharmacopoeia, Her Majesty's Stationery Office, London, 2 (2003) p 1257.

[10] The United States Pharmacopoeial Convention, Rockville, MD, The United States Pharmacopoeia 24th edn. The National Formulary 19 (2000) p 1104.

[11] P. D. Panzade, K. R. Mahadlik, East Pharm. 43 (2000) 115. [12] P. Nagaraja, K. R. Sunitha, R. A. Vasantha, H. S. Yathirajan, J. Pharm. Biomed. Anal. 28 (2002) 527.

[13] T. Saffaj, A. Charrouf, Y. Abourriche, A. abboud, M. B. Bennamara, Formaco. 59 (2004) 843.

[14] D. M. Joshi, A. P. joshi, J. Indian. Chem. Soc.74 (1997) 585.

[15] B. A. Moussa, Int. J. Pharm. 10 (1982) 199.

[16] T.P. Gandhi, P. R. Patel, V. C. Patel, S. K. Patel, J. Inst. Chem. 56 (1984) 127.

[17] C.S.P. Sastry, M. Aruna, A. R. M. Rao, Talanta. 35 (1988) 23. [18] C.S.P. Sastry, M. Aruna, A. R. M. Rao, A. S. R. P. Tipirneni, Chem. Anal. 36 (1991) 153.

[19] A. S.Amin, Anal. Lett. 30 (1997) 2503.

[20] P. Nagaraja, K. R. Sunitha, R. A. Vasantha, H. S. Yathirajan, J. Pharm. Biomed. Anal. 28 (2002) 527.

[21] N. D. Dinesh, P. Nagaraj, K. S. Rangappa, Turk. J. Chem. 28 (2004) 335.

[22] A. Rehaman, A. S. Ijaz, A. Raza, J. Iran. Chem. Soc. 2 (2005) 197.

[23] F. Bluemenhal, Biochem.Z. 28 (1956) 1321.

[24] G. O. Burr, R. A. Gartner, J. Am. Chem. Soc. 46 (1924) 1224.

[25] W. Frieber, Centr. Baktenol. Parasitenk. 87 (1922) 254.

[26] Chem. Rev. 26 (1940) 324.

[27] R. Wasicky, Z. Anal. Chem. 54 (1915)

[28] Raymond-Hamlet, Bull. Sci. Pharmacol. 33 (1926) 447.

[29] A. E. A. Werner, Sci. Proc, Roy. Dulbin Soc. 23 (1944) 214.

[30] K. Kapse, G. Prabhakar, S. Appala raju, Indian. J. Pharm. Sci. 3 (2006) 403.

[31] B. H. Ahmed, O.O. Johnson, J. Pharmacy and Bioresources. 1(2004) 1.

[32] B. H. M. Mruthyunjayaswamy, S. M. Malipatil, S. Appala Raju, J. Indian. Chem. Soc. 18 (2001) 60. 